\title{
Persistent Nonbilious Vomiting in a Child: Possible Duodenal Webbing
}

\author{
Rossella Angotti ${ }^{1}$, Francesco Molinaro ${ }^{1}$, Giovanni Cobellis ${ }^{2}$, Carmine Noviello ${ }^{2}$, Caterina Bocchi ${ }^{3}$, Francesco Ferrara', \\ Edoardo Bindi ${ }^{1}$ and Mario Messina ${ }^{1}$ \\ ${ }^{1}$ Division of Pediatric Surgery, Department of Medical, Surgical and Neurological Sciences, University of Siena, Siena, ${ }^{2}$ Pediatric Surgery \\ Unit, Academic Salesi Children Hospital, Marche Polytechnic University, Ancona, ${ }^{3}$ Section of Obstetrics and Gynecology, Department of \\ Molecular and Developmental Medicine, University of Siena, Siena, Italy
}

An association between malrotation and congenital duodenal webbing is rare. We present our experience with four patients at two centers, and a review of published reports. There are currently 94 reported cases of duodenal pathology associated with malrotation. However, only 15 of the 94 cases (15.9\%) include patients with malrotation and a duodenal web. We suggest that nonbilious vomiting in a child must prompt the surgeon to consider duodenal pathology even in the presence of malrotation. Clin Endosc 2017;50:191-196

Key Words: Congenital duodenal web; Malrotation; Child; Nonbilious vomiting

\section{INTRODUCTION}

Midgut malrotation is a potential cause of bowel obstruction in children. A symptomatic association between a malrotation and a congenital duodenal web is rare and few cases have been reported in the literature. The true incidence of malrotation is not fully known; however, it is reported as approximately 1 in 500 live births. ${ }^{1,2}$ The incidence of duodenal web as a cause of intestinal obstruction is reported to be between 1:10,000 to $1: 40,000{ }^{3,4}$ There is a high incidence (approximately 50\%) of associated anomalies in patients with intrinsic duodenal obstruction, but malrotation is reported to occur in only in $19.7 \%$ of cases. ${ }^{4}$ We present our experience with four patients at two centers (Siena and Ancona) and a review of the literature.

Received: June 30, 2016 Revised: August 14, 2016

Accepted: September 3, 2016

Correspondence: Rossella Angotti

Division of Pediatric Surgery, Department of Medical, Surgical and Neurological Sciences, University of Siena, Viale Bracci 16, Siena 53100, Italy

Tel: +39-577-586502, Fax: +39-577-586174, E-mail: rossellaangotti@me.com

(c) This is an Open Access article distributed under the terms of the Creative Commons Attribution Non-Commercial License (http://creativecommons.org/ licenses/by-nc/3.0) which permits unrestricted non-commercial use, distribution, and reproduction in any medium, provided the original work is properly cited.

\section{CASE REPORTS}

\section{Case 1}

A 2-year-old girl was transferred to our clinic with a history of nonbilious vomiting since 2 months of age and loss of weight $(8.8 \mathrm{~kg})$. On admission, the patient's vital signs were normal. On physical examination, her abdomen was soft and nontender with no peritoneal signs. Her anus was normal and an abdominal ultrasound was normal. An upper gastrointestinal contrast study revealed a duodenal obstruction. Laparotomy was performed and a distended duodenum with the cecum and appendix at the left upper quadrant fixed by Ladd's bands was found. Ladd's procedure was performed and the appendix was removed. The patient's postoperative course was normal.

Two months after surgery, she was hospitalized for persistent diarrhea and nonbilious vomiting. An upper gastrointestinal contrast study was performed and it showed delayed gastroduodenal emptying. Esophagogastroduodenoscopy revealed a duodenal web with a small central defect that we attempted to manage endoscopically (endoscopic resection) with no success (Fig. 1). Parental nutrition (PN) was started and a second laparotomy was performed. The duodenum was opened and the antimesenteric border of the duodenal web 

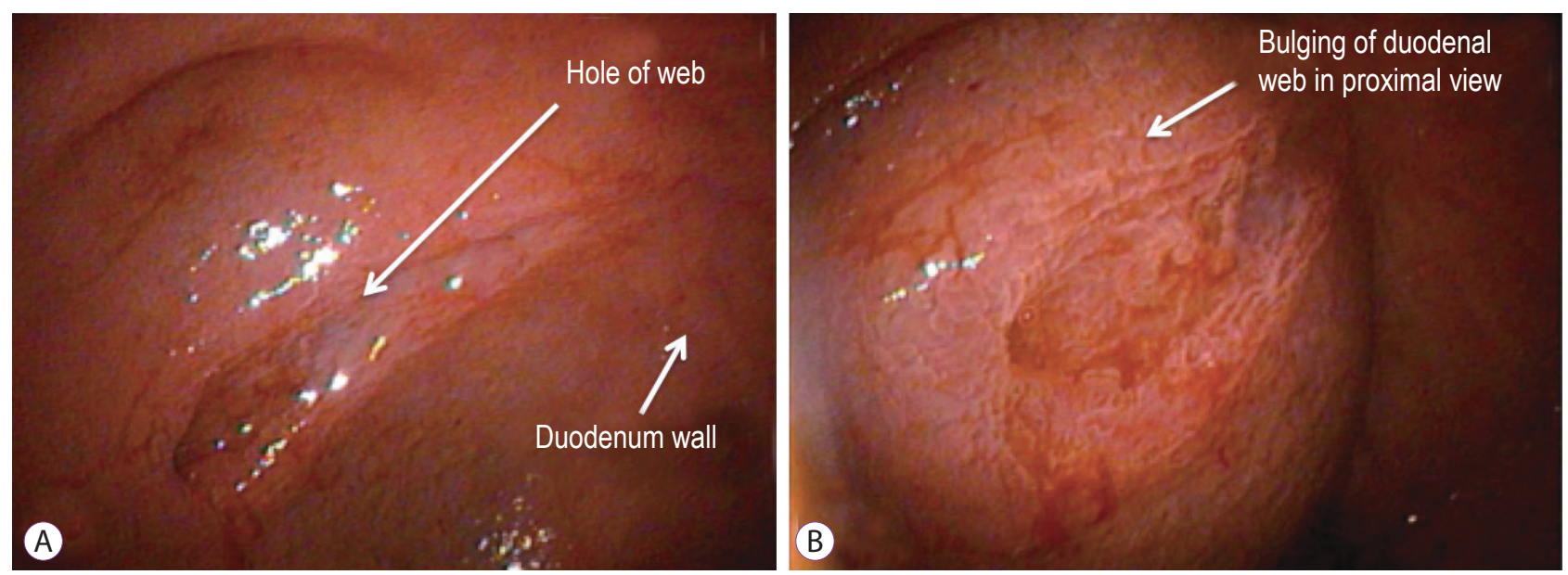

Fig. 1. Case 1: 2-year-old girl. (A, B) An endoscopic picture of her congenital duodenal web. This is a view during an endoscopic procedure. (B) The tag shows the bulging of the duodenal web.
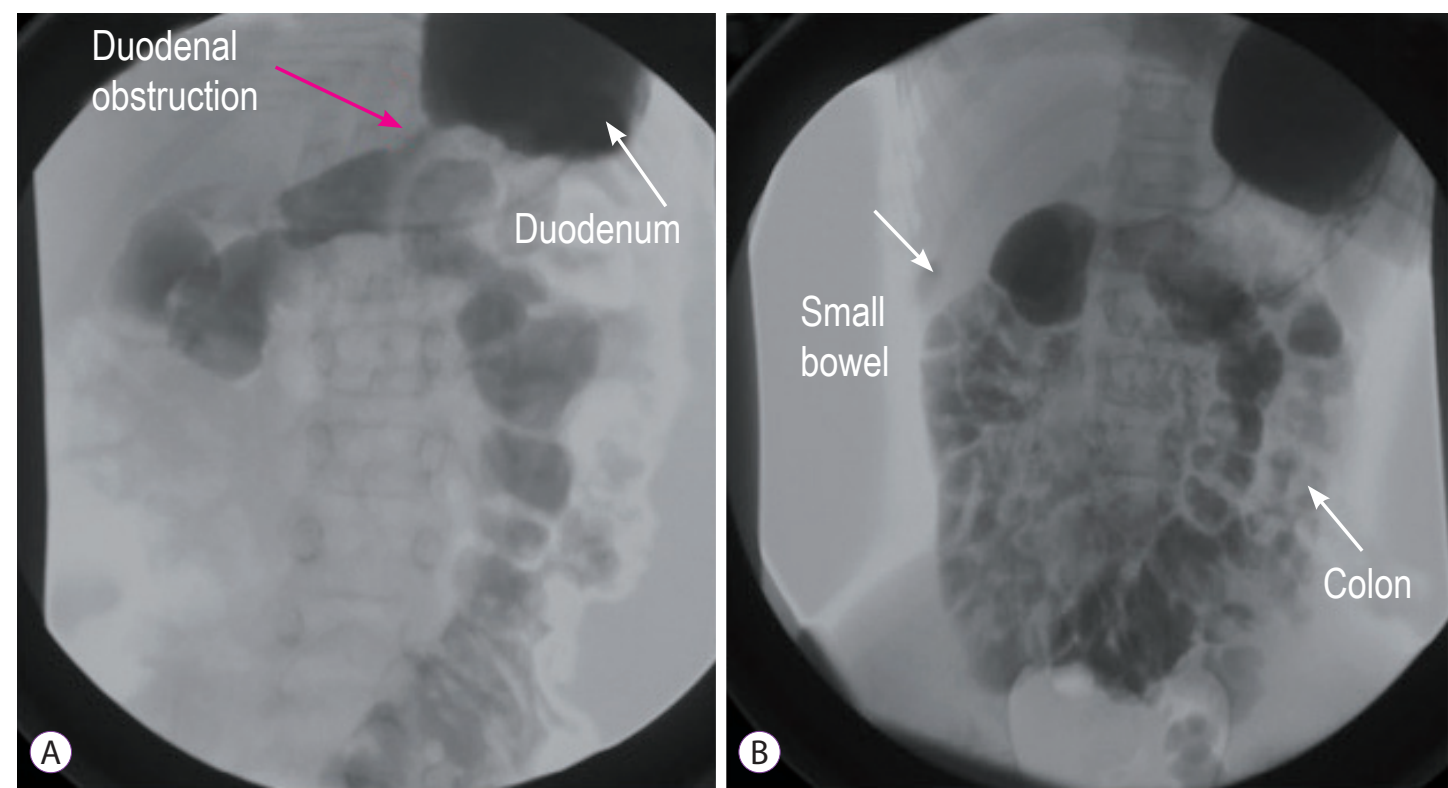

Fig. 2. Case 3: 10-year-old girl. (A, B) An upper gastrointestinal contrast study shows a duodenal stenosis with delayed emptying of the 2nd duodenal portion (red arrow) and all of the small bowel in the right quadrant and the colon in the left quadrant because of a previous Valdoni's procedure.

was excised; a side-to-side duodenoduodenostomy was completed. The patient tolerated full oral feeding on day 6 after surgery. The PN was withdrawn on the postoperative day 10 and she was discharged on day 11. At last follow-up, 4 weeks after discharge, the patient had gained $900 \mathrm{~g}$ and she fed without problems.

\section{Case 2}

A 5-day-old boy, delivered by caesarian for fetal bradycardia, was evaluated for nonbilious vomiting since birth and loss of $10 \%$ of his birth weight $(2,980 \mathrm{~g})$. Normal meconium passing was noted. Malrotation was suspected based on an upper gastrointestinal X-ray analysis. An echocardiogram analysis ruled out any congenital cardiac anomalies. The patient underwent laparotomy that showed a middle distended duodenum with the cecum and appendix at the left upper quadrant fixed by Ladd's bands. Ladd's procedure and an appendectomy were performed. The absence of bile in the nasogastric tube and failure to pass a nasogastric tube through the duodenum led us to perform a duodenotomy. Opening of the duodenum showed a large duodenal web with a blind pouch. Distal to the web, the duodenum was normal. The duodenal web was resected and the duodenum was closed. The patient was transferred to the neonatal intensive care unit. The nasogastric tube was left in place for 5 days and PN was provided. An upper gastrointestinal exam was performed on postoperative day 8 

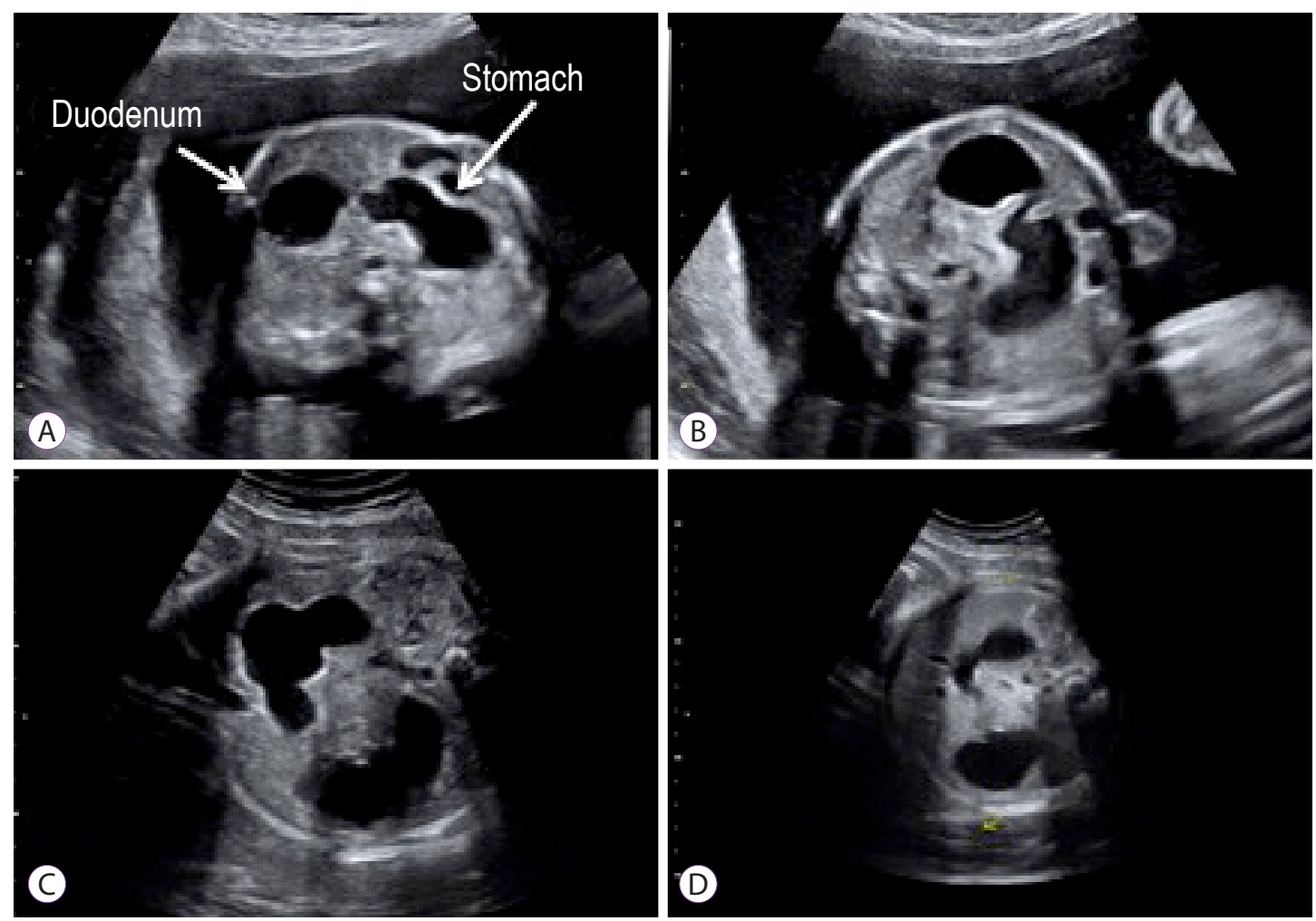

Fig. 3. Case 4. (A-D) Prenatal ultrasound shows the presence of a double bubble that was suspected to be a duodenal pathology.

and it showed no leakage. Oral feeding was started and it was tolerated well. He was discharged home on postoperative day 28 with a weight of 3,620 g. Two weeks post discharge the patient was breastfeeding normally with an increase in weight to $4,020 \mathrm{~g}$.

\section{Case 3}

A 10-year-old girl came to our outpatient clinic for persistent nonbilious vomiting since birth. She had trisomy 21. She had been operated on for malrotation at 8 months (Valdoni's procedure) and for duodenal stenosis at 9 months (duodenotomy and resection of a congenital web). She underwent laparoscopic adhesiolysis for bowel obstruction at age 5 . An upper gastrointestinal contrast study showed a duodenal stenosis with delayed emptying of the 2 nd duodenal portion with all of the small bowel in the right quadrant and the colon in the left quadrant due to the previous Valdoni's procedure (Fig. 2). Esophagogastroduodenoscopy was performed and it confirmed the persistence of the duodenal web. We planned a laparotomy and performed a side-to-side jejunal duodenum anastomosis. After 24 hours in pediatric intensive care, the patient was transferred to our ward, where oral feeding was started with a gradual increase day by day. She was discharged on postoperative day 10 , with complete tolerance of the oral diet. At outpatient follow-up, 1 month after discharge, she took food and drinks orally without difficulty and she did not experience any vomiting.

\section{Case 4}

A 1-day-old boy was evaluated for prenatal diagnosis of a double bubble (Fig. 3). After birth, radiography showed an enlarged stomach and duodenum and air in the distal bowel. An upper gastrointestinal series revealed an incomplete duodenal obstruction. Surgery confirmed the presence of a congenital duodenal web and revealed the presence of malrotation. An esophagogastroduodenoscopy was performed and the procedure confirmed the persistence of the duodenal web. We performed a Ladd's procedure and duodenotomy with resection of the web. His postoperative course was normal. The nasogastric tube was left in place for 5 days and PN was administered. An upper gastrointestinal exam was performed on postoperative day 7 and it showed no leakage. Oral feeding was started and it was tolerated well. He was discharged home on postoperative day 19 . He will attend the outpatient clinic in a month.

\section{DISCUSSION}

A symptomatic malrotation usually presents during in- 
Table 1. Data Collected from a Review of the Literature

\begin{tabular}{|c|c|c|c|c|c|c|}
\hline Study & $\begin{array}{l}\text { No. of } \\
\text { patient }\end{array}$ & Sex & Malformation & Clinical picture & $\begin{array}{c}\text { Time of } \\
\text { diagnosis }\end{array}$ & Treatment \\
\hline $\begin{array}{l}\text { Madding et } \\
\text { al. }(1950)^{8}\end{array}$ & $1 / 1$ & $\mathrm{~F}$ & $\begin{array}{l}\text { Congenital atresia of the third } \\
\text { portion of the duodenum and } \\
\text { malrotation of the intestine }\end{array}$ & $\begin{array}{l}\text { Projectile vomiting since } \\
\text { birth of bile-stained } \\
\text { material following oral } \\
\text { feedings. A meconi- } \\
\text { um stool had passed. } \\
\text { Physical examination } \\
\text { revealed upper abdom- } \\
\text { inal distention. }\end{array}$ & $\begin{array}{l}9 \text { Days of } \\
\text { life }\end{array}$ & Duodenojejunostomy \\
\hline
\end{tabular}

\begin{tabular}{|c|c|c|c|c|c|c|}
\hline $\begin{array}{l}\text { Baumgartner } \\
\text { et al. }(1992)^{9}\end{array}$ & $1 / 1$ & M & $\begin{array}{l}\text { Duodenal atresia, annular pancreas, } \\
\text { malrotation small glottic region }\end{array}$ & $\begin{array}{l}\text { Non projectile non bil- } \\
\text { ious emesis }\end{array}$ & $\begin{array}{l}7 \text { Days of } \\
\text { life }\end{array}$ & $\begin{array}{l}\text { Pyloroduodenostomy was } \\
\text { performed resulting in cure }\end{array}$ \\
\hline $\begin{array}{l}\text { Barrack et al. } \\
(1993)^{10}\end{array}$ & $2 / 62$ & - & Duodenal atresia and malrotation & - & - & - \\
\hline $\begin{array}{l}\text { Zerin et al. } \\
(1994)^{11}\end{array}$ & $2 / 17$ & - & Duodenal atresia and malrotation & - & - & - \\
\hline $\begin{array}{l}\text { Samuel et al. } \\
(1997)^{12}\end{array}$ & $\begin{array}{l}36 / 64 \\
5 / 36\end{array}$ & - & $\begin{array}{l}\text { Duodenal atresia and duodenal } \\
\text { stenosis and malrotation } \\
\text { Malrotation and web wind sock }\end{array}$ & $\begin{array}{l}\text { Bilious vomiting and } \\
\text { upped abdominal } \\
\text { distension }\end{array}$ & - & $\begin{array}{l}\text { Duodenoduodenostomy and } \\
\text { Ladd's procedure, appendi- } \\
\text { cectomy }\end{array}$ \\
\hline $\begin{array}{l}\text { Dalla Vecchia } \\
\text { et al. }(1998)^{13}\end{array}$ & $\begin{array}{l}39 / 138 \\
9 / 39\end{array}$ & - & $\begin{array}{l}\text { Duodenal atresia or stenosis and } \\
\text { malrotation } \\
\text { Malrotation and web wind sock }\end{array}$ & - & - & $\begin{array}{l}\text { Duodenoduodenostomy, du- } \\
\text { odenotomy (web excision), } \\
\text { and duodenojejunostomy }\end{array}$ \\
\hline $\begin{array}{l}\text { Chandran et } \\
\text { al. }(1999)^{14}\end{array}$ & $1 / 1$ & $\mathrm{~F}$ & $\begin{array}{l}\text { Multiple organ malrotation syn- } \\
\text { drome with duodenal atresia }\end{array}$ & $\begin{array}{l}\text { Bile-stained vomiting and } \\
\text { marked dehydration }\end{array}$ & $\begin{array}{l}3 \text { Days of } \\
\text { life }\end{array}$ & Duodenoplasty \\
\hline $\begin{array}{l}\text { Pumberger et } \\
\text { al. }(2002)^{15}\end{array}$ & $4 / 4$ & $\mathrm{~F}$ & $\begin{array}{l}\text { Duodeno-jejunal atresia associated } \\
\text { with malrotation, volvulus, and } \\
\text { absent parietal attachment of the } \\
\text { mesentery }\end{array}$ & - & - & - \\
\hline $\begin{array}{l}\text { Glüer et al. } \\
(2002)^{16}\end{array}$ & $1 / 1$ & $\mathrm{~F}$ & $\begin{array}{l}\text { Duodenal atresia due to annular } \\
\text { pancreas and intestinal, partially } \\
\text { volvulated malrotation }\end{array}$ & $\begin{array}{l}\text { Persistence of nonbilious } \\
\text { emesis }\end{array}$ & - & $\begin{array}{l}\text { Laparoscopic reduction of } \\
\text { the volvulated bowel loops, } \\
\text { division of obstructing } \\
\text { bands, and creation of a } \\
\text { side-to-side duodenoduo- } \\
\text { denostomy }\end{array}$ \\
\hline $\begin{array}{l}\text { Aslanabadi et } \\
\text { al. }(2007)^{17}\end{array}$ & $3 / 30$ & - & $\begin{array}{l}\text { 2-Malrotation with duodenal atresia } \\
\text { 1-Malrotation with Meckel's diver- } \\
\text { ticulum and duodenal atresia }\end{array}$ & - & - & \\
\hline $\begin{array}{l}\text { Morikawa et } \\
\text { al. }(2009)^{18}\end{array}$ & $2 / 2$ & $\mathrm{~F}$ & $\begin{array}{l}\text { Anorectal malformation, } \\
\text { Hirschprung, malrotation, and } \\
\text { duodenal stenosis } \\
\text { Trisomy 21, meconium peritoni- } \\
\text { tis, duodenal atresia by annular } \\
\text { pancreas (prenatal diagnosis), } \\
\text { malrotation (postnatal) }\end{array}$ & - & $\begin{array}{l}1 \text { Day of } \\
\text { life } \\
2 \text { Days of } \\
\text { life }\end{array}$ & $\begin{array}{l}\text { First surgery: Ladd's pro- } \\
\text { cedure, endorectal pull- } \\
\text { throught and cutback } \\
\text { anoplasty; second surgery: } \\
\text { duodenoduodenostomy } \\
\text { Duodenoduodenostomy, } \\
\text { Ladd's procedure, colostomy }\end{array}$ \\
\hline $\begin{array}{l}\text { Patil et al. } \\
\qquad(2011)^{19}\end{array}$ & $1 / 1$ & $\mathrm{~F}$ & $\begin{array}{l}\text { Duodenal atresia with apple-peel } \\
\text { configuration of the remaining } \\
\text { small intestine, an absent superior } \\
\text { mesenteric artery, and associated } \\
\text { malrotation }\end{array}$ & $\begin{array}{l}\text { Bilious vomit and janjuice } \\
\text { since birth }\end{array}$ & $\begin{array}{l}7 \text { Days of } \\
\text { life }\end{array}$ & $\begin{array}{l}\text { Ladd's procedure and duode- } \\
\text { nojejunostomy }\end{array}$ \\
\hline $\begin{array}{l}\text { Eksarko et al. } \\
\qquad(2013)^{20}\end{array}$ & $1 / 1$ & $\mathrm{~F}$ & $\begin{array}{l}\text { Congenital duodenal web and } \\
\text { malrotation }\end{array}$ & $\begin{array}{l}\text { Abdominal distension } \\
\text { and history of having } \\
\text { not passed meconium }\end{array}$ & $\begin{array}{l}1 \text { Day of } \\
\text { life }\end{array}$ & $\begin{array}{l}\text { Ladd's procedure and duode- } \\
\text { notomy }\end{array}$ \\
\hline
\end{tabular}


Table 2. Data Collected from Our Series

\begin{tabular}{lccccc}
\hline $\begin{array}{l}\text { No. of } \\
\text { patient }\end{array}$ & Gender & Malformations & Clinical picture & $\begin{array}{c}\text { Time of } \\
\text { diagnosis }\end{array}$ & Treatment \\
\hline $1 / 4$ & F & $\begin{array}{c}\text { Malrotation and congenital } \\
\text { duodenal web }\end{array}$ & $\begin{array}{c}\text { Nonbilious vomiting since 2 } \\
\text { months and loss of weight }\end{array}$ & 2-Month-old & $\begin{array}{c}\text { Duodenotomy and resection of duo- } \\
\text { denal web; a side-to-side duodeno- } \\
\text { duodenostomy }\end{array}$ \\
\hline $1 / 4$ & M & $\begin{array}{c}\text { Malrotation and congenital } \\
\text { duodenal web }\end{array}$ & $\begin{array}{c}\text { Nonbilious vomiting since } \\
\text { birth and loss of } 10 \% \text { of his } \\
\text { birth weight (2,980 g) }\end{array}$ & 5-Day-old & Duodenotomy and web resection \\
$1 / 4$ & F & $\begin{array}{c}\text { Malrotation and congenital } \\
\text { duodenal web }\end{array}$ & $\begin{array}{c}\text { Persistent non bilious vomit- } \\
\text { ing }\end{array}$ & 9-Month-old & Duodenotomy and web resection \\
\hline $1 / 4$ & M & $\begin{array}{c}\text { Malrotation and congenital } \\
\text { duodenal web }\end{array}$ & $\begin{array}{c}\text { Prenatal diagnosis of double } \\
\text { bubble }\end{array}$ & 1-Day-old & Duodenotomy and web resection \\
\hline
\end{tabular}

fancy or during the neonatal period; however, many cases are reported at older ages. ${ }^{4}$ An early diagnosis is important because of the high risk of a life-threatening midgut volvulus. ${ }^{4}$ The most common presentation of malrotation is bilious vomiting due to duodenal obstruction from intermittent midgut volvulus rather than compression by Ladd's bands or kinking of the duodenum. ${ }^{4}$ However, in some patients, malrotation is discovered incidentally during radiographic studies or during laparotomy performed for other indications. $^{1,2,5,6}$

Congenital duodenal obstruction is a frequent cause of congenital intestinal obstruction in the newborn, occurring in 1 per 5,000 to 10,000 live births, affecting boys more commonly than girls. ${ }^{4}$ Duodenal obstruction results from either intrinsic or extrinsic lesions. More than $50 \%$ of patients with duodenal atresia or duodenal stenosis have associated congenital anomalies, especially Down syndrome, which is present in around $30 \%$ of duodenal obstruction patients. ${ }^{4}$ The associated malformations in order of frequency are Down syndrome, annular pancreas, congenital heart disease, malrotation, esophageal atresia, urinary tract malformation, anorectal anomalies, other bowel atresias, vertebral anomalies, and musculoskeletal anomalies. These associated malformations have an impact on the morbidity and mortality of these patients. ${ }^{3,4,7}$

The intent of this report was to focus on the uncommon but possible association between intestinal malrotation and intrinsic duodenal obstruction (19.7\% of cases). ${ }^{5}$ Our review of the literature is summarized in Table $1 .^{8-20}$ Through this brief review, it is clear that since 1950 an association between duodenal malformation and intestinal malrotation has been noted. However, it is evident from the review that this association is uncommon highlighting the difficulty associated with preoperative diagnosis. There are currently 94 reported cases of duodenal malformation associated with malrotation. However, only 15 of 94 (16\%) include patients with malro- tation and duodenal webbing. The four cases of the present study (Table 2) add to the literature and further support the idea that during the surgical treatment of a patient with duodenal obstruction, it is necessary to exclude the co-occurrence of malrotation and intrinsic duodenal pathology to avoid having to perform two surgeries in a short period.

We performed a retrospective analysis of our series. The first case affirms that the clinical and imaging picture of the patient was discordant with the initial diagnosis. The baby was referred to us with nonbilious vomiting and failure to thrive since birth. An initial suspicion of a pyloric stenosis was unlikely based on the history and it was ruled out based on ultrasound and laparotomy observations. During the first laparotomy, intestinal malrotation without volvulus was found; however, this could not explain the clinical findings of nonbilious vomiting and metabolic alkalosis. A classic malrotation "usually" presents with bilious vomiting because the obstruction is under Vater's papilla. The absence of bilious vomiting should have alerted us to the possibility that a second pathology at the level of the gastric antrum or proximal duodenum was present, which was confirmed during the second surgery. An esophagogastroduodenoscopy could have aided the diagnosis.

The second case showed the correct management of a child with nonbilious vomiting and intraoperative confirmation of Ladd's band. In the presence of malrotation, on the basis of the absence of bile in the nasogastric tube and the impossibility of passing a nasogastric tube through the duodenum, we explored the duodenum and found the duodenal web. The third case, as in the first, demonstrated wrong initial management because the patient underwent two different surgeries. The last case was a simple paradigmatic case because the presence of the duodenal web and malrotation was an incidental finding during surgery. Esophagogastroduodenoscopy established the correct diagnosis.

In conclusion, we suggest that an incidental finding should 
not distract surgeons from finding the underlying pathology. Indeed, even if some associations are described as rare and uncommon, they could occur in a patient. Nonbilious vomiting in a child must prompt the surgeon to consider a duodenal pathology even in the presence of malrotation. A preoperative esophagogastroduodenoscopy, when it is possible, is a good approach for surgeons to confirm the presence of a duodenal web. The alternative, duodenal exploration is imperative to exclude the involvement of a duodenum web as the cause of vomiting.

\section{Conflicts of Interest}

The authors have no financial conflicts of interest.

\section{REFERENCES}

1. Ingoe R, Lange P. The Ladd's procedure for correction of intestinal malrotation with volvulus in children. AORN J 2007;85:300-308.

2. Angotti R, Bulotta AL, Ferrara F, et al. Uncommon surgical emergencies in neonatology. Pediatr Med Chir 2014;36:99.

3. Beeks A, Gosche J, Giles H, Nowicki M. Endoscopic dilation and partial resection of a duodenal web in an infant. J Pediatr Gastroenterol Nutr 2009;48:378-381.

4. Sweed Y. Duodenal obstruction. In: Puri P, Höllwarth ME, eds. Pediatric surgery: diagnosis and management. London: Springer; 2009. p. 383392.

5. Lampl B, Levin TL, Berdon WE, Cowles RA. Malrotation and midgut volvulus: a historical review and current controversies in diagnosis and management. Pediatr Radiol 2009;39:359-366.

6. Penco JM, Murillo JC, Hernández A, De La Calle Pato U, Masjoan DF, Aceituno FR. Anomalies of intestinal rotation and fixation: consequences of late diagnosis beyond two years of age. Pediatr Surg Int 2007;23:723-730

7. Yoon $\mathrm{CH}$, Goo HW, Kim EA, Kim KS, Pi SY. Sonographic windsock sign of a duodenal web. Pediatr Radiol 2001;31:856-857.
8. Madding GF, Everhart MW, Heath J. Congenital duodenal atresia with malrotation of the intestine; a case successfully treated by duodeno-jejunostomy. Ann Surg 1950;131:433-436.

9. Baumgartner F, Moore TC. Atretic, obstructive proximal duodenal mass associated with annular pancreas and malrotation in a newborn male. Eur J Pediatr Surg 1992;2:42-44.

10. Barrack SM, Kyambi JM, Ndungu J, Wachira N, Anangwe G, Safwat S. Intestinal atresia and stenosis as seen and treated at Kenyatta national hospital, Nairobi. East Afr Med J 1993;70:558-564.

11. Zerin JM, Polley TZ Jr. Malrotation in patients with duodenal atresia: a true association or an expected finding on postoperative upper gastrointestinal barium study? Pediatr Radiol 1994;24:170-172.

12. Samuel M, Wheeler RA, Mami AG. Does duodenal atresia and stenosis prevent midgut volvulus in malrotation? Eur J Pediatr Surg 1997;7:1112.

13. Dalla Vecchia LK, Grosfeld JL, West KW, Rescorla FJ, Scherer LR, Engum SA. Intestinal atresia and stenosis: a 25-year experience with 277 cases. Arch Surg 1998;133:490-496.

14. Chandran H, Upadhyay V, Pease PW. Multiple organ malrotation syndrome with duodenal atresia: a case report. Pediatr Surg Int 1999;15:6162.

15. Pumberger W, Birnbacher R, Pomberger G, Deutinger J. Duodeno-jejunal atresia with volvulus, absent dorsal mesentery, and absent superior mesenteric artery: a hereditary compound structure in duodenal atresia? Am J Med Genet 2002;109:52-55

16. Glüer S, Petersen C, Ure BM. Simultaneous correction of duodenal atresia due to annular pancreas and malrotation by laparoscopy. Eur J Pediatr Surg 2002;12:423-425.

17. Aslanabadi S, Ghalehgolab-Behbahan A, Jamshidi M, Veisi P, Zarrintan S. Intestinal malrotations: a review and report of thirty cases. Folia Morphol (Warsz) 2007;66:277-282

18. Morikawa N, Kuroda T, Honna T, et al. A novel association of duodenal atresia, malrotation, segmental dilatation of the colon, and anorectal malformation. Pediatr Surg Int 2009;25:1003-1005.

19. Patil RT, Gupta R, Parelkar SV, et al. A rare case of duodenal atresia with apple-peel configuration of the small intestine and malrotation. Eur J Pediatr Surg 2011;21:340-342.

20. Eksarko P, Nazir S, Kessler E, et al. Duodenal web associated with malrotation and review of literature. J Surg Case Rep 2013;2013. 